\title{
Pattern of Glucose Tolerance among Patients with Peripheral Spondyloarthritis
}

\author{
A T M Tanveer Hasan ${ }^{1}$, Al-Mamun ${ }^{2}$ \\ ${ }^{1}$ Assistant Professor of Rheumatology, Enam Medical College \& Hospital, Savar, Dhaka; ${ }^{2}$ Rheumatology Registrar, Enam \\ Medical College \& Hospital, Savar, Dhaka
}

\begin{abstract}
$>$ Background \& Objectives:

Peripheral spondyloarthritis is a variant of spondyloarthritis which usually has a chronic course. There is an increased risk of cardiovascular diseases among patients with chronic inflammatory diseases in general. Coexisting diabetes mellitus can potentially add to the risk. The objective of this study was to determine the frequency of glucose intolerance in patients with spondyloarthritis
\end{abstract}

\section{$>$ Materials \& Methods:}

The study was conducted among 35 participants with peripheral spondyloarthritis who visited the Department of Rheumatology, Enam Medical College \& Hospital, Savar, Dhaka, Bangladesh from September, 2018 to January, 2020. The participants underwent either oral glucose tolerance test or estimation of HbA1C.

\section{$>$ Results:}

The mean age of participants was 43.96 years. The majority $(80 \%)$ of them were young to muddle-aged ( $\leq 40$ years). $22.9 \%$ of the participants were prediabetic. Diabetes mellitus was found to be present in $37.1 \%$ of the participants. There was no significant difference between the study population and the general population in terms of frequency of prediabetes. But the frequency of diabetes in the study population was higher than that in the general population. There was no significant difference between males and females with regard to the frequencies of prediabetes and DM. Moreover, there was no significant difference in the frequencies of prediabetes and DM between young and middle-aged to elderly population.

\section{$>$ Conclusion:}

Considering the greater burden of DM among patients with peripheral spondyloarthritis across all age groups, routine screening for DM may be indicated in these individuals.

Keywords:- Peripheral Spondyloarthritis, Prediabetes, Diabetes Mellitus.

\section{INTRODUCTION}

The spondyloarthritis (SpA) family consists of ankylosing spondylitis (AS), nonradiographic axial SpA (nr-axSpA), peripheral SpA, psoriatic arthritis, SpA associated with Crohn's disease and ulcerative colitis, reactive arthritis and juvenile-onset SpA. The smaller number of patients with predominantly peripheral manifestations of $\mathrm{SpA}$ (eg, arthritis, enthesitis, and dactylitis, rather than back and spine pain) who do not meet established classification criteria for AS, reactive arthritis, psoriatic arthritis, or SpA related to inflammatory bowel disorders can be considered as having peripheral $\mathrm{SpA}^{1}$. Only about 12 to 30 percent of SpA patients overall may exhibit predominantly peripheral $\mathrm{SpA}^{2}$. The point prevalence of spondyloarthritis in Bangladesh is $1.2 \%{ }^{3}$.

The reasons for the classification of SpA into categories are both historical and practical, but each category does not necessarily represent a discrete entity the clinical, laboratory, and imaging findings can overlap. The diagnosis and management approaches for patients suspected of having any type of SpA are also similar in general $^{4,5}$.

The major clinical features which differentiate spondyloarthritis ( $\mathrm{SpA}$ ) from other forms of arthritis are the distribution and type of musculoskeletal manifestations and certain extraarticular features. Patients with axial SpA characteristically have chronic low back pain. Patients with either axial or peripheral SpA can exhibit peripheral musculoskeletal features, which include dactylitis (sausage digits), enthesitis (heel pain and/or swelling), and peripheral arthritis ${ }^{1}$.

In addition to having articular and extraarticular features, ankylosing spondylitis increases the risk of ischaemic heart disease and stroke ${ }^{6,7}$. Similarly psoriatic arthritis increases the risk of preclinical atherosclerosis and overt cardiovascular disease ${ }^{8}, 9$. DM is more common among patients with psoriatic arthritis in comparison with the general population ${ }^{10}$. But no study has yet been conducted to assess DM as a comorbidity in patients with peripheral spondyloarthritis. Our study assessed the frequencies of both prediabetes and diabetes in patients with axial spondyloarthritis visiting a tertiary care hospital and compared the results with those in the general Bangladeshi population. 
ISSN No:-2456-2165

\section{MATERIALS \& METHODS}

This study was conducted in the Department of Rheumatology of Enam Medical College \& Hospital, Savar, Dhaka, Bangladesh from September 2018 to January 2020. 35 patients with peripheral spondyloarthritis were recruited and they underwent either oral glucose tolerance test (OGTT) or estimation of HbA1C. The relatively small sample size was due to a small proportion of individuals with spondyloarthritis as a whole having purely peripheral involvement. Diabetes mellitus and prediabetes were defined using criteria described in table 1 as per recommendations of World Health Organization (WHO) and American Diabetes Association (ADA) ${ }^{11,}{ }^{12}$. Individuals satisfying any of the criteria for prediabetes or DM were classified into the respective category.

\begin{tabular}{|c|c|c|c|}
\hline Category & $\begin{array}{c}\text { Fasting Plasma Glucose } \\
(\mathbf{m m o l} / \mathbf{L})\end{array}$ & $\begin{array}{c}\text { Plasma Glucose 2 Hours } \\
\text { after 75g of Glucose } \\
(\mathbf{m m o l} / \mathbf{L})\end{array}$ & HbA1C(\%) \\
\hline Prediabetes & $6.1-6.9$ & $7.8-<11.1$ & $5.7-6.4 \%$ \\
\hline Diabetes Mellitus & $\geq 7$ & $\geq 11.1$ & $\geq 6.5 \%$ \\
\hline
\end{tabular}

Table 1:- Citeria for Prediabetes \& Diabetes Mellitus

\section{RESULT}

Ages of the participants ranged from 21 to 65 years. Mean age was 43.96 years. The participants were divided into three groups according to their ages: young (18-40 years), middle aged ( $>40-60$ years) and elderly ( $>60$ years). $80 \%$ of the participants were young to middle-aged. Figure 1 demonstrates the details of distribution of the participants across different age groups.

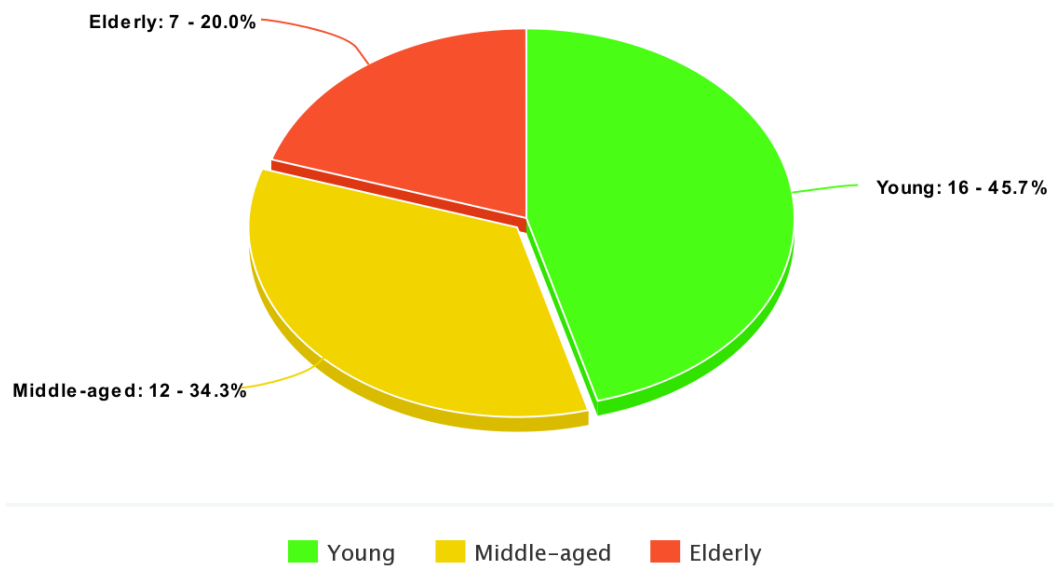

Fig 1:- Distribution of the Participants across Different Age Groups

$57.1 \%$ of the participants were males and $42.9 \%$ were females. So the majority of the respondents were males.

Figure 2 below shows the pattern of glucose tolerance among participants.

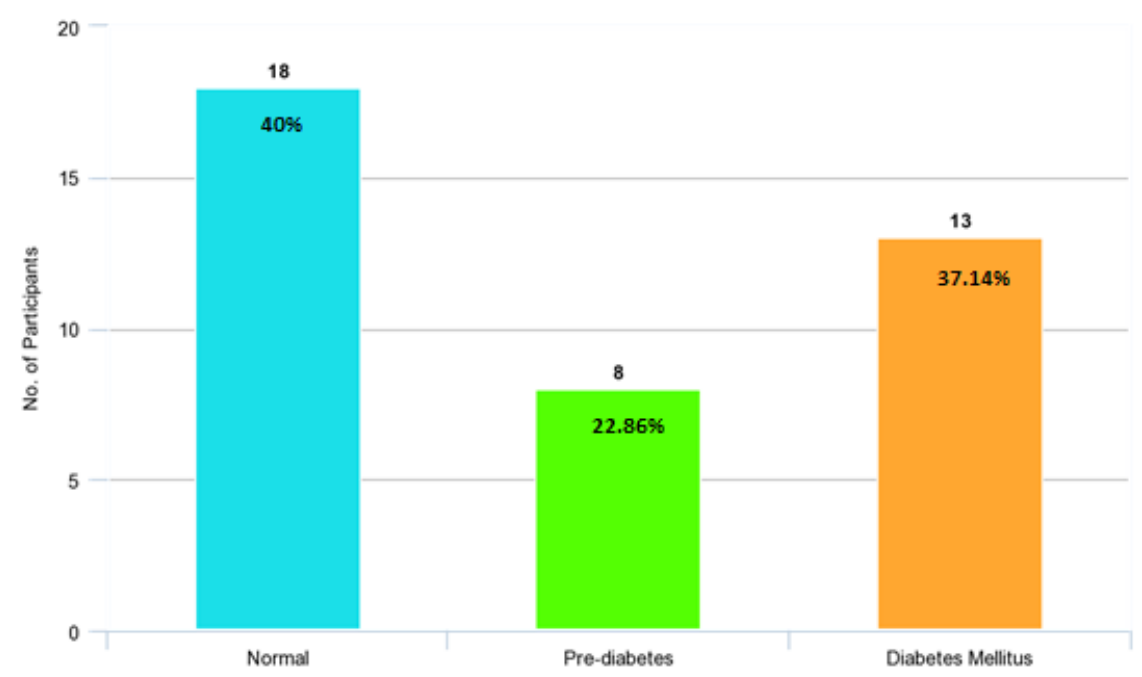

Fig 2:- Pattern of Glucose Tolerance among Participants 
There was no significant difference $(\mathrm{p} \approx 0.98)$ between the frequency of prediabetes in our study $(22.86 \%)$ and the prevalence of prediabetes, which was about $23 \%$ according to a nationwide survey among 7541 Bangladeshi individuals ${ }^{13}$. On the other hand, the frequency of DM among patients with axial SpA in our study (37.1\%) was significantly higher $(\mathrm{p} \approx 0.0001)$ than the national prevalence of $\mathrm{DM}$, which is about $10 \%$.

Table 2 shows gender wise distribution of participants across different patterns of glucose tolerance (normal/prediabetes/diabetes mellitus).

\begin{tabular}{|c|c|c|c|}
\hline \multirow{2}{*}{ Sex } & \multicolumn{3}{|c|}{ Pattern of Glucose Tolerance } \\
\cline { 2 - 4 } & Normal & Prediabetes & Diabetes Mellitus \\
\hline Female & 5 & 4 & 6 \\
\hline Male & 9 & 4 & 7 \\
\hline
\end{tabular}

Table 2:- Patterns of Glucose Tolerance among Males \& Females

$20 \%$ of the males were prediabetic and $35 \%$ of the males were diabetic. Among the female participants, $26.67 \%$ had prediabetes and $40 \%$ had diabetes. There was no significant difference between males and females with respect to the frequency of prediabetes $(\mathrm{p} \approx 1.00)$ and $\mathrm{DM}$ $(\mathrm{p} \approx 0.7)$.

Table 3 shows the patterns of glucose tolerance across different age groups.

\begin{tabular}{|c|c|c|c|c|}
\hline \multirow[t]{2}{*}{ Age Group } & \multicolumn{3}{|c|}{ Pattern of Glucose Tolerance } & \multirow[t]{2}{*}{ Total } \\
\hline & Normal & Prediabetes & DM & \\
\hline $\begin{array}{c}\text { Young } \\
\text { (18-40 years) }\end{array}$ & $\begin{array}{c}9 \\
(56.25 \%)\end{array}$ & $\begin{array}{c}3 \\
(18.75 \%)\end{array}$ & $\begin{array}{c}4 \\
(25 \%)\end{array}$ & $\begin{array}{c}16 \\
(100 \%)\end{array}$ \\
\hline $\begin{array}{c}\text { Middle-Aged to Elderly (>40 } \\
\text { years) }\end{array}$ & $\begin{array}{c}5 \\
(26.31 \%)\end{array}$ & $\begin{array}{c}5 \\
(26.31 \%)\end{array}$ & $\begin{array}{c}9 \\
(47.37 \%)\end{array}$ & $\begin{array}{c}19 \\
(100 \%)\end{array}$ \\
\hline
\end{tabular}

Table 3:- Glucose Tolerance Patterns across Different Age Groups

There was no significant difference between youngaged and middle-aged to elderly groups in terms of frequencies of prediabetes $(p \approx 0.7)$ and diabetes $(p \approx 0.29)$.

\section{DISCUSSION}

Diabetes is a major public health problem worldwide, especially in low-and-middle income countries, where more than $80 \%$ of people reside ${ }^{14,15}$. According to the estimate of International Diabetes Federation (IDF), the global prevalence of diabetes among adults in 2013 was $8.3 \%$, which is 382 million people living with diabetes and projected to increase beyond 592 million in less than 25 years ${ }^{14}$. The IDF Diabetes Atlas 5 th edition projected that the prevalence of Bangladesh will rise to more than $50 \%$ by next 15 years and that will place Bangladesh as the 8th highest diabetic populous country in the world ${ }^{15}$.

A nationwide survey $(n=7541)$ among people in Bangladesh conducted in 2011 revealed that the prevalence of prediabetes was about $23 \%$ and that of diabetes was about $10 \%^{13}$. The frequency of prediabetes among peripheral SpA patients was similar to that in the general population, but the burden of diabetes was much higher. Although there has been no such study so far on patients with peripheral spondyloarthritis, similar findings were observed in patients with ankylosing spondylitis. For instance, Liao et al. demonstrated higher incidence of DM among patients with ankylosing spondylitis ${ }^{16}$. Another study conducted by Chen et al showed an increased risk of diabetes among patients with ankylosing spondylitis ${ }^{17}$.

The majority of our participants were young to middle-aged as expected ${ }^{18}$. There was no difference between males and females with regard to the frequencies of prediabetes and DM as in the general population ${ }^{13}$. In contrast with the greater prevalence of prediabetes and DM in the middle-aged to elderly people from the general population, our sudy showed similar frequencies of prediabetes and DM across young and middle-aged to elderly groups ${ }^{19}, 20$. This may be indicative of an increased risk of developing prediabetes and diabetes in young patients with peripheral spondyloarthritis in comparison with the general young population.

EULAR recommends vaccination of individuals with autoimmune inflammatory rheumatic diseases (AIIRDs) including spondyloarthritis considering the increased risk of infections in these individuals resulting from an immunosuppressive effect of the underlying AIIRD and the use of immunomodulatory drugs to treat the AIIRD ${ }^{21}$. The risk of infections is also increased in patients with $\mathrm{DM}^{22}$. Moreover, both DM and chronic inflammatory diseases increase the risk of cardiovascular diseases ${ }^{23,}{ }^{24}$. As our study demonstrated increased frequency of DM among patients with axial $\mathrm{SpA}$, we would like to recommend routine screening of individulas in this disorder for DM as an important measure to reduce the risk of infections and cardiovascular diseases. 


\section{CONCLUSION}

There is a greater frequency of DM in patients with peripheral spondyloarthritis compared with that in the general population. Routine screening for the presence of diabetes mellitus should be a part of evaluation of these individuals in the clinical settings.

\section{REFERENCES}

[1]. Yu DT, van Tubergen A. Overview of the clinical manifestations and classification of spondyloarthritis. UpToDate. Sieper J, Romain PL, ed. Maltham, MA: UpToDate Inc. Available from: https://www.uptodate.com/contents/overview-of-theclinical-manifestations-and-classification-ofspondyloarthritis?search=an $\% 20$ overview\%20of\%20c linical\%20manifestations $\% 20$ and $\% 20$ classification $\% 2$ 0of $\% 20$ spondyloarthritis\&source=search_result\&sele ctedTitle $=1 \sim 150 \&$ usage_type $=$ default\&display_rank $=$ 1 (Updated 7 September 2018, cited 17 December 2019)

[2]. Yu DT, van Tubergen A. Clinical manifestations and diagnosis of peripheral spondyloarthritis in adults. UpToDate. Sieper J, Romain PL, ed. Maltham, MA: UpToDate Inc. Available from: https://www.uptodate.com/contents/clinicalmanifestations-and-diagnosis-of-peripheralspondyloarthritis-inadults?search=peripheral\%20spondyloarthritis\&sourc e=search_result\&selectedTitle=1 19\&usage_type=def ault\&display_rank=1\#H39 (Updated 7 March 2018, cited January 2020)

[3]. Ahmed S, Haq SA, Al-qadir AZ, Rahman MM, Paul S. Survey on prevalence of rheumatic disorders in Bangladeshi adults. Ann Rheum Dis. 2017;76(2): 1044-1045

[4]. Zeidler H, Amor B. The Assessment in Spondyloarthritis International Society (ASAS) classification criteria for peripheral spondyloarthritis and for spondyloarthritis in general: the spondyloarthritis concept in progress. Ann Rheum Dis 2011; 70:1.

[5]. Zeidler H, Calin A, Amor B. A historical perspective of the spondyloarthritis. Curr Opin Rheumatol 2011; 23:327.

[6]. Essers I, Stolwijk C, Boonen A, De Bruin ML, Bazelier MT, de Vries F, van Tubergen A. Ankylosing spondylitis and risk of ischaemic heart disease: a population-based cohort study. Ann Rheum Dis. 2016;75(1):203.

[7]. Mathieu S, Soubrier M. Cardiovascular events in ankylosing spondylitis: a 2018 meta-analysis. Annals of the Rheumatic Diseases. 2019;78(6):e57.

[8]. Tam LS, Shang Q, Li EK, Tomlinson B, Chu TT, Li M, Leung YY, Kwok LW, Wong KC, Li TK, Yu T. Subclinical carotid atherosclerosis in patients with psoriatic arthritis. Arthritis Care \& Research: Official Journal of the American College of Rheumatology. 2008;59(9):1322-31.
[9]. Jamnitski A, Symmons D, Peters MJ, Sattar N, MciInnes I, Nurmohamed MT. Cardiovascular comorbidities in patients with psoriatic arthritis: a systematic review. Annals of the rheumatic diseases. 2013 Feb 1;72(2):211-6.

[10]. Eder L, Chandran V, Cook R, Gladman DD. The risk of developing diabetes mellitus in patients with psoriatic arthritis: a cohort study. The Journal of rheumatology. 2017 Mar 1;44(3):286-91.

[11]. World Health Organization. International Diabetes Federation (2006) Definition and diagnosis of diabetes mellitus and intermediate hyperglycemia: report of a WHO/IDF consultation. IDF consultation. 2008.

[12]. American Diabetes Association. 2. Classification and diagnosis of diabetes: standards of medical care in diabetes-2019. Diabetes Care. 2019 Jan 1;42(Supplement 1):S13-28.

[13]. Akter S, Rahman MM, Abe SK, Sultana P. Prevalence of diabetes and prediabetes and their risk factors among Bangladeshi adults: a nationwide survey. Bulletin of the World Health Organization. 2014 Jan 10;92:204-13A.

[14]. Aguiree F, Brown A, Cho N, Dahlquist G, Cho D, Dodd D. Whiting (2013) IDF Diabetes Atlas. IDF Diabetes Atlas, 6th Edition, International Diabetes Federation, Basel.2013;74-90.

[15]. Islam SM, Purnat TD, Phuong NT, Mwingira U, Schacht K, Fröschl G. Non-Communicable Diseases (NCDs) in developing countries: a symposium report. Globalization and health. 2014 Dec;10(1):81.

[16]. Liao K, Kuo Y, Lai S. Diabetes mellitus in ankylosing spondylitis. Annals of the Rheumatic Diseases Published Online First: 06 September 2019.

[17]. Chen HH, Yeh SY, Chen HY, Lin CL, Sung FC, Kao $\mathrm{CH}$. Ankylosing spondylitis and other inflammatory spondyloarthritis increase the risk of developing type 2 diabetes in an Asian population. Rheumatology international. 2014 Feb 1;34(2):265-70.

[18]. Brent HL. Ankylosing spondylitis and undifferentiated spondyloarthropathy. Medscape. Diamond HS, ed. New York, NY: Medscape LLC. Available from: https://emedicine.medscape.com/article/332945overview\#a1 (Updated 3 September 2019, cited January 2020)

[19]. Khardori R. Type 2 diabetes mellitus. Medscape. Griffing GT, ed. New York, NY: Medscape LLC. Available from: https://emedicine.medscape.com/article/117853overview\#a1 (Updated 4 December 2019, cited January 2020)

[20]. The Centre for Disease Control. National diabetes statistics report 2017. 2017. Available from: https://www.cdc.gov/diabetes/data/statisticsreport/index.html (Cited January 2020) 
[21]. Furer V, Rondaan C, Heijstek MW, Agmon-Levin N, van Assen S, Bijl M, Breedveld FC, D'Amelio R, Dougados M, Kapetanovic MC, van Laar JM. 2019 update of EULAR recommendations for vaccination in adult patients with autoimmune inflammatory rheumatic diseases. Annals of the rheumatic diseases. 2020 Jan 1;79(1):39-52.

[22]. Casqueiro J, Casqueiro J, Alves C. Infections in patients with diabetes mellitus: A review of pathogenesis. Indian journal of endocrinology and metabolism. 2012 Mar;16(Suppl1):S27.

[23]. Gregg EW, Li Y, Wang J, Rios Burrows N, Ali MK, Rolka D, Williams DE, Geiss L. Changes in diabetesrelated complications in the United States, 19902010. New England Journal of Medicine. 2014 Apr 17;370(16):1514-23.

[24]. Hansen, P. R. Chronic inflammatory diseases and atherosclerotic cardiovascular disease: Innocent bystanders or partners in crime? Curr. Pharm. Des. 2018. 24(3): 281-290 